\title{
ENERGY COSTS
}

\section{Trickle down taxation}

Appl. Econ. 12, 303-342 (2020)

A better understanding of how changes in input costs are transferred to consumers of industrial products would help determine how carbon taxes might also affect the price of these industrial products. Sharat Ganapati at Georgetown University, and Reed Walker and Joseph Shapiro at the University of California, Berkeley, now use data from the US Census of Manufactures to show that only about $70 \%$ of industrial energy price increases are passed through to consumers.

The researchers use unit prices and input costs for six industries: boxes, bread, cement, concrete, gasoline refining and plywood. They build a partial equilibrium model and study the effects of changes in fuel prices (obtained from US Energy Information Administration data) on industrial output prices in the short to medium term. They take into account the grid energy mix at any given time. The researchers find that a US\$1 increase in energy prices translates to a US\$0.7 increase in output product prices on average. The range of cost increase passed through to consumers in the various industries studied is $25-75 \%$. Their model shows that in industries using a wide array of inputs in markets that are not perfectly competitive, pass-through of increased prices is not $100 \%$. This phenomenon should be taken into account when modelling the potential impact of carbon taxation on consumption.

Fouad Khan

Published online: 20 May 2020

https://doi.org/10.1038/s41560-020-0627-4 